\section{EL SISTEMA INTERAMERICANO DE PROTECCIÓN A LOS DERECHOS HUMANOS Y DERECHOS DE LAS VÍCTIMAS EN LAS TRANSICIONES DEMOCRÁTICAS: REFLEXIONES SOBRE EL DERECHO A LA REPARACIÓN INTEGRAL*}

\author{
THE INTER-AMERICAN SYSTEM OF HUMAN \\ RIGHTS PROTECTION AND THE RIGHTS OF \\ VICTIMS IN DEMOCRACY TRANSITIONS: \\ REFLECTION ABOUT THE RIGHT TO \\ REPARATION
}

O SISTEMA INTERAMERICANO DE PROTEÇÃO DOS DIREITOS HUMANOS E OS DIREITOS DAS VÍTIMAS EM TRANSIÇÕES DEMOCRÁTICAS: REFLEXÕES SOBRE 0 DIREITO À REPARAÇÃO INTEGRAL

\section{RESUMEN}

El trámite de casos ante el Sistema Interamericano ha sido importante para la exigibilidad de derechos desde la sociedad civil. Además, el Sistema ha implementado acciones estratégicas que contribuyen a establecer el sentido y alcance de los Derechos Humanos y los valores democráticos en los países. En este artículo se efectúa una aproximación inicial a la intervención estratégica del Sistema Interamericano en los últimos años a través de sus mecanismos y procedimientos, así como en algunos retos y potencialidades para promover el acceso a la justicia de las víctimas de violaciones a los derechos humanos en el contexto de las dinámicas complejas del derecho global. El análisis hace énfasis en la promoción

\footnotetext{
* Artículo producto de investigación en el marco del proyecto "Democracia y justicia en los sistemas de protección a los derechos humanos: Un balance de las funciones de monitoreo a los derechos humanos del Sistema Interamericano y de los mecanismos de vigilancia y supervisión de los tratados de derechos humanos de Naciones Unidas, reflexiones a partir de la situación colombiana. 1991-2014" que se encuentran desarrollando los autores.

a. Doctor en sociología jurídica e instituciones políticas. Master en Estudios Políticos del Instituto de Estudios Políticos y Relaciones Internacionales -IEPRI de la Universidad Nacional de Colombia. Especialista en sociología jurídica, Universidad Externado de Colombia. Abogado, Universidad Nacional y Licenciado en Ciencias Sociales, Universidad Distrital Francisco José de Caldas. Profesor Asociado de la Facultad de Derecho Universidad Nacional de Colombia. Docente de la Maestría en Derecho, Universidad La Gran Colombia.

b. Abogado y Magister en Derecho de la Universidad Nacional de Colombia. Profesor de la facultad de Jurisprudencia de la Universidad Colegio Mayor de Nuestra señora del Rosario, y de la Facultad de Derecho de la Universidad la Gran Colombia.
}

Jorge Enrique Carvajal Martínez ${ }^{a}$ jecarvajalma@gmail.com Andrés Mauricio Guzmán Rincón andres.guzman@ugc.edu.co Fecha de recepción: 18 de noviembre de 2015 Fecha de revisión: 2 de diciembre de 2015 Fecha de aceptación: 7 de diciembre de 2015

\footnotetext{
MISIÓN JURÍDICA

Revista de Derecho y Ciencias Sociales Bogotá, D.C. (Colombia)

Colaboradores Externos Nacionales

Núm. 10 Año 2016

Enero - Junio, pp. 181 - 193

ISSN 1794-600X
} 
del derecho a la reparación integral a partir de las transiciones democráticas en la región $\mathrm{y}$, específicamente, de los estándares proferidos por la Corte Interamericana a partir de casos contra el Estado colombiano.

\section{PALABRAS CLAVES}

Acceso a la justicia, Sistema Interamericano de Derechos Humanos, derecho a la reparación integral.

\begin{abstract}
This paper is an advanced research of the investigation project "Democracy and justice systems to protect human rights", the problem addressed is to establish what is the meaning of the integral reparations and its development around the role that the American System of Human Rightshas had. The main conclusion that we show is that the American System of Human Rights, through its jurisprudence has developed new instances of international conflict resolution in the context of a significant increase in the demand for justice in human rights.
\end{abstract}

\section{KEYWORDS}

Access to justice, Inter-American Human Rights, the right to integral reparations.

\section{RESUMO}

0 trâmite dos processos perante o Sistema Interamericano tem sido importante para a exigibilidade dos direitos da sociedade civil. Além disso, o sistema tem implementado ações estratégicas que contribuem para estabelecer o sentido e o alcance dos direitos humanos e dos valores democráticos nos países. Este artigo apresenta uma abordagem inicial à intervenção estratégica do Sistema Interamericano nos últimos anos, através de seus mecanismos e procedimentos, bem como alguns desafios e potenciais para promover o acesso à justiça para as vítimas de violações dos direitos humanos no contexto da dinâmica complexa do direito global. A análise destaca a promoção do direito à compensação integral, a partir das transições democráticas na região e, especificamente, as normas proferidas pela Corte Interamericana de Direitos Humanos em processos contra o Estado colombiano.

\section{PALAVRAS-CHAVE}

Acesso à justiça, Sistema Interamericano de Direitos Humanos, direito à reparação integral.

\section{INTRODUCCIÓN}

Desde 1919, con la creación de la Sociedad de Naciones, el derecho internacional público comenzó a tener una gran influencia en la protección de los derechos humanos; desde entonces, las convenciones que suscribieron los Estados se convirtieron paulatinamente en instrumentos que fueron adoptando una mayor fuerza jurídica. Estos compromisos, principalmente en asuntos relacionados con la seguridad social y la protección a los trabajadores comenzaban a ser parte de la legislación interna y al mismo tiempo, su cumplimiento podía ser exigido ante organismos internacionales (García, 2004).

Con el fin de la Segunda Guerra Mundial, el papel del Derecho Internacional Público se acentúo notablemente. Emergen instrumentos como la Declaración Universal de los Derechos del Hombre de 1948 y la Convención Americana sobre Derechos Humanos de 1969, conocida como Pacto de San José de Costa Rica que promueven el desarrollo de mecanismos de protección de los Derechos Humanos en el seno de instituciones como la Organización de las Naciones Unidas -ONU-, y la Organización de Estados Americanos -OEA- en el nivel regional. Asimismo y de manera reciente, surge la Corte Penal Internacional, a partir de lo dispuesto en el Estatuto de Roma, y cuyo objetivo principal consiste en sancionar penalmente a los individuos de los Estados que hayan cometido los crímenes más graves, de mayor trascendencia, para la comunidad internacional.

Estos hechos denotan un claro reconocimiento de los Derechos Humanos en el plano nacional e internacional, en el que los organismos internacionales han tenido un rol protagónico en su promoción y defensa, así como en el fortalecimiento del acceso a la justicia. Precisamente este último será el eje principal en torno al cual se efectúa en el presente trabajo, un análisis del rol del Sistema Interamericano de Protección a los Derechos Humanos en los últimos años, teniendo en cuenta que este ha sido un mecanismo muy utilizado por parte de la sociedad civil en la búsqueda del restablecimiento de derechos y el afianzamiento de los valores democráticos frente al abuso o la inoperancia de 
los Estados en la región, lo que lo ha convertido en un organismo importante en el desarrollo de procesos de democratización en las últimas décadas, en particular se hará énfasis en la potencialidad de estos espacios para fortalecer las exigencias de justicia de las víctimas de crimines de lesa humanidad en los contextos transicionales que se han venido configurando en la región.

El orden de la exposición trazado es el siguiente:

En la primera parte se pone de presente la importancia de la emergencia de mecanismos de protección de los derechos humanos como un desarrollo del acceso a la justicia, para posteriormente destacar la variación en la orientación estratégica del sistema interamericano y cómo esta se ha visto reflejada en su organización interna y el desempeño de sus funciones. Básicamente se advierte el paso de la denuncia y documentación de las graves violaciones a derechos humanos durante los regímenes autoritarios, hacia el acompañamiento de la transición política durante la década de los ochenta y finalmente la superación de las desigualdades estructurales y la protección a las minorías. Lo anterior, permite defender un punto de vista más comprensivo en el que se sostiene que la reivindicación del derecho a la reparación integral no es exclusiva de la superación de las dictaduras o los regímenes autoritarios, ya que su potencial se extiende frente a los desafíos de la adopción de la democracia en la región. Así las cosas, a pesar de las limitaciones propias de los órganos de justicia, se identifican algunas posibilidades de promover la democracia y los derechos a través de la ampliación del acceso a la justicia global a través del Sistema Interamericano de Derechos Humanos.

Mientras que en la segunda, a partir del análisis de dos sentencias paradigmáticas proferidas por la Corte Interamericana de Derechos Humanos en las que se delimita el sentido y alcance del derecho a al reparación integral en lo que concierne a la responsabilidad del Estado colombiano frente a las violaciones a los derechos humanos en medio del conflicto armado, se ilustrará la forma a través de la cual el Sistema Interamericano de Derechos Humanos ha sido un vehículo imprescindible en las luchas sociales frente al poder político en las últimas décadas. Sin duda los mecanismos de los que dispone le han permitido a las víctimas del conflicto armado, contar con un espacio relevante para acceder a la justicia y promover iniciativas de transformación política al interior de los Estados, bajo las cuales se logra ampliar la exigibilidad de derechos hacia la búsqueda del fortalecimiento de la democracia y los derechos humanos.

\section{METODOLOGÍA}

Metodológicamente el artículo aborda dos componentes: en primer lugar, a partir del estudio de la bibliografía especializada, identificar algunas trayectorias históricas que ha adelantado el Sistema Interamericano como escenario de resolución de conflictos en la región y su posicionamiento como instrumento que posibilita el acceso a la justicia de las víctimas de violaciones a los derechos humanos. En segundo lugar, y como consecuencia del primer aspecto, se propone aproximar estos elementos a partir del análisis de dos sentencias paradigmáticas proferidas por la Corte Interamericana y que recoge las demandas de justicia de las víctimas a través de este mecanismo, estableciendo estándares para la comprensión del sentido y alcance del derecho a la reparación integral, así como de la responsabilidad del Estado por violaciones a los Derechos humanos en el contexto de conflicto armado y bajo las cuales se evidencia que este mecanismo de protección ha tenido no solo una significativa importancia en la superación de conflictos armados o regímenes autoritarios, sino que también contribuyen al fortalecimiento de la democracia y la superación de desigualdades estructurales.

\section{El derecho humano de acceso a la justicia}

La reflexión sobre el acceso a los sistemas jurídicos nacionales e internacionales por parte de los individuos, surge desde el momento mismo en que estos son considerados sujetos del derecho internacional. Básicamente el derecho de acceso a la justicia se define como la posibilidad concreta de todas las personas, sin ninguna distinción, a obtener el restablecimiento de sus derechos a través de los medios dispuestos por la administración de justicia, los cuales deben ser efectivos, adecuados, oportunos, sencillos y serios.

Los primeros antecedentes de este derecho se encuentran en los artículos 8 y 10 de la Declaración Universal de los Derechos humanos, donde se consagra la facultad que tiene toda 
persona de acudir ante los estrados judiciales ya sea en calidad de víctima ${ }^{1}$ o de procesado ${ }^{2}$, caso en el cual se respetarán las normas referidas al debido proceso ${ }^{3}$.

Aunque en un comienzo el derecho de acceso a la justicia tuvo extensos desarrollos en lo relacionado con las garantías de los procesados, con el transcurrir del tiempo el ejercicio de éste derecho se fue orientando hacia la protección de las víctimas y de sus familiares en el transcurso de un proceso judicial. Así por ejemplo, se expidieron normas específicas como los Principios y Directrices Básicos sobre el Derecho de las Víctimas de Violaciones de las Normas Internacionales de Derechos Humanos y del Derecho Internacional Humanitario a Interponer Recursos y Obtener Reparaciones; la Declaración sobre los Principios Fundamentales de Justicia para las Víctimas de Delitos y del Abuso de Poder; o los Principios para la Protección y la Promoción de los Derechos Humanos mediante la Lucha contra la Impunidad.

De estos instrumentos internacionales se derivan derechos tales como: i) gozar de un recurso efectivo; ii) contar con un tribunal competente, independiente e imparcial, en donde la víctima o sus familiares sean oídos públicamente y con las garantías debidas; iii) que se le brinden condiciones de seguridad y respeto a su integridad y dignidad a lo largo del proceso; iv) contar con una investigación seria que implique identificar y sancionar a los autores materiales, intelectuales y encubridores, y v) el deber correlativo de las víctimas de obtener una reparación plena, integral o satisfactoria, exigiendo que esa sanción sea en todo caso de naturaleza penal; vi) a que la investigación sea efectiva, imponiendo al Estado el deber de apelar a

1. Declaración Universal de los Derechos Humanos. Art. 8. "Toda persona tiene derecho a un recurso efectivo ante los tribunales nacionales competentes, que la ampare contra actos que violen sus derechos fundamentales reconocidos por la constitución o por la ley".

2. Declaración Universal de los Derechos Humanos. Art. 10. "Toda persona tiene derecho, en condición de plena igualdad, a ser oída públicamente y con justicia por un tribunal independiente $e$ imparcial, para la determinación de sus derechos y obligaciones o para el examen de cualquier acusación contra ella en materia penal".

3. Declaración Universal de los Derechos Humanos. Art. 11. "Toda persona acusada de delito tiene derecho a que se presuma su inocencia mientras no se pruebe su culpabilidad, conforme a la ley y en juicio público en el que se le hayan asegurado todas las garantías necesarias para su defensa". todos los recursos técnicos, tecnológicos y humanos disponibles con el fin de identificar o individualizar, capturar, procesar y sancionar a los culpables; vii) al debido proceso; viii) a que se siga un juicio justo, rápido, sencillo y ajustado a plazos razonables ; ix) a la verdad, la reparación integral y la no repetición de las conductas violatorias de los derechos; $\mathrm{x}$ ) a la participación, toda vez que las víctimas y sus familiares pueden y deben cumplir un rol activo y propositivo a lo largo de todas las etapas del proceso penal, de tal manera que cuentan con amplias facultades para formular pretensiones y aportar o disputar el acervo probatorio y, finalmente, xi) a la información (Serrano, 2011) ${ }^{5}$.

Como se puede apreciar, el derecho de acceso a la justicia tiene una estrecha relación con los derechos a la verdad, a la justicia y a la reparación integral de las víctimas, ya que prácticamente se constituye en una garantía y en un medio concreto para lograr su efectividad.

Así las cosas, el acceso al sistema de la administración de justicia interna es un elemento fundamental para la realización de los derechos consagrados en las cartas políticas, su importancia radica en que es el medio para la consecuente materialización del derecho. En esa medida, aspectos como el conocimiento del derecho, los costos procesales, los buenos servicios jurídicos y la aplicación de las medidas dictadas por los jueces cuando culmina el caso, son aspectos imprescindibles para su análisis (PNUD: 2005; 7).

Teniendo en cuenta estos desarrollos normativos, es posible concebir un concepto del derecho de acceso a la justicia que comprende un ámbito y alcance más amplios, al adoptar una preocupación central por el logro de una efectiva protección y restitución de derechos de las personas. Lo que conlleva a que su análisis no puede limitarse a la consagración formal de estos derechos en las normas, sino que se

4. En este sentido, la Corte Interamericana de Derechos Humanos en sentencia del 11 de mayo de 2007, Caso de la masacre de la Rochela vs. Colombia, señaló: "el derecho de acceso a la justicia debe asegurar, en tiempo razonable, el derecho de las personas víctimas o sus familiares, a que se haga todo lo necesario para conocer la verdad de lo sucedido y para que se sancione a los eventuales responsables".

5. Para un desarrollo sistemático de los principales estándares internacionales en materia de acceso a la justicia con especia énfasis en los derechos de los niños consultar Serrano, 2011. 
preocupa por contrarrestar la existencia de prácticas discriminatorias y de las demás barreras que impiden su consecución. En esa medida la comprensión del derecho de acceso a la justicia involucra una perspectiva socio-jurídica e institucional que permite abarcar su complejidad.

1.1 Apuntes para una caracterización de los organismos del Sistema Interamericano de Protección a los Derechos Humanos

La Convención Americana de Derechos Humanos, que entró en vigor en 1978 y ha sido ratificada por 25 países de la región, consagra los derechos humanos que los Estados se comprometen internacionalmente a respetar, así como a proporcionar garantías para su ejercicio. Este instrumento además establece los mecanismos de acceso a esta jurisdicción, el procedimiento que se debe agotar ante sus instancias y adopta las principales funciones y competencias de los organismos que conforman el Sistema Interamericano ${ }^{6}$.

El Sistema Interamericano de Derechos Humanos (SIDH) ha tenido en la última década un rol muy importante en la internacionalización de los sistemas jurídicos en la región, extendiendo su competencia a más países que han aceptado la jurisdicción de la Corte Interamericana como recientemente lo han hecho México y Brasil. De igual forma, en buena medida, la Convención Americana goza actualmente de rango constitucional o superior respecto de los sistemas jurídicos de los países. Además, en los últimos años ha habido un uso recurrente del sistema por parte de abogados, jueces, operadores jurídicos, funcionarios y activistas sociales; de igual forma es una práctica consolidada que los Estados acudan a las decisiones y precedentes de la Corte Interamericana en los debates sobre políticas públicas y en las controversias jurídicas internas, lo que ha conllevado a que los tribunales nacionales apliquen los parámetros de la Corte IDH y de los estándares del Sistema en materia de derechos humanos. Por ejemplo, en Perú las decisiones sobre la invalidez de

6. El artículo 33 de éste instrumento señala que: "Son competentes para conocer de los asuntos relacionados con el cumplimiento de los compromisos contraídos por los Estados Partes en esta Convención: a) la Comisión Interamericana de Derechos Humanos, llamada en adelante la Comisión, y b) la Corte Interamericana de Derechos Humanos, llamada en adelante la Corte". las leyes de amnistía de graves violaciones de derechos humanos, se constituyeron en el soporte jurídico a la apertura de los procesos judiciales contra los responsables de crímenes de lesa humanidad ${ }^{7}$, mientras que en Argentina los jueces fundamentaron sus decisiones en este precedente para decretar la invalidez de las leyes de obediencia debida y punto final ${ }^{8}$. Por su parte, en Colombia, las decisiones y los parámetros del Sistema Interamericano le sirvieron a la Corte Constitucional para fijar el marco de justicia transicional bajo el cual se efectuó la desmovilización de los grupos paramilitares en $2005^{9}$ (Abramovich, 2010).

1.2 El Sistema Interamericano en contexto: de las violaciones masivas a los patrones estructurales de desigualdad

El Sistema Interamericano ha jugado un rol diferente de acuerdo a cada momento histórico que ha afrontado, en los que es posible diferenciar las prioridades temáticas y las características de sus estrategias de intervención. Abramovich (2010) distingue tres periodos clave para comprender el papel del sistema en la región, un primer periodo que coincide con las dictaduras y

7. Al respecto ver la Sentencia de la Corte Interamericana de Derechos Humanos caso Barrios Altos vs Perú.

8. Al respecto ver la sentencia de la Corte Suprema de Justicia de Argentina que resuelve el caso Simón, Julio Héctor y otros de 14 de junio de 2005.

9. En los últimos años, la justicia transicional ha tenido unos desarrollos muy importantes en Colombia. Las discusiones jurídicas, políticas, sociales y éticas han girado en torno a la necesidad e importancia de terminar con el conflicto armado y dar el paso definitivo hacia la reconciliación y la paz, pero garantizando los derechos de las víctimas a la verdad a la justicia y a la reparación integral. Instrumentos normativos como la Ley 975 de 2005 "Por la cual se dictan disposiciones para la reincorporación de miembros de grupos armados organizados al margen de la ley, que contribuyan de manera efectiva a la consecución de la paz nacional y se dictan otras disposiciones para acuerdos humanitarios" acentuaban su perspectiva en el victimario, estableciendo una serie de beneficios jurídicos en favor de los miembros de grupos armados ilegales que se desmovilizaran efectivamente y que colaboraran con la consecución de la verdad, pero con un déficit importante en materia de verdad, justicia y reparación a las víctimas, precisamente la Corte Constitucional mediante la Sentencia C-370 de 2006 señaló con precisión en qué consistía este déficit y se esforzó por ajustar esta norma a los estándares internacionales en la materia, que prohíben la impunidad frente a los crímenes de lesa humanidad y de guerra y establecen una serie de obligaciones en cabeza de los Estados para garantizar los derechos de las víctimas. En dicho fallo la Corte Constitucional tuvo en cuenta no solo los múltiples precedentes jurisprudenciales de la Corte Interamericana sobre el asunto, sino que también incorporó a su razonamiento los pronunciamientos de la Comisión Interamericana de Derechos Humanos sobre la garantía del derecho a la verdad durante el proceso de desmovilización de los grupos paramilitares en Colombia. 
el terrorismo de Estado en la región, un segundo periodo que es el de las transiciones democráticas y los procesos de reparación y un tercer periodo en el que en muchas regiones se ha logrado la transición hacia la democracia, pero en el que aún es necesario el fortalecimiento de estos procesos.

En sus inicios el Sistema Interamericano debió enfrentar violaciones masivas y sistemáticas a los DDHH, cometidas bajo regímenes autoritarios como los que se instauraron en el cono sur a partir de las dictaduras, o en el marco de conflictos armados internos. Su rol fue, el de convertirse en un último recurso de justicia para las víctimas de esas violaciones, que no podían acudir a sistemas de justicia internos incapaces o manipulados. Los Informes de países de la Comisión sirvieron para documentar situaciones con rigor técnico, y legitimar las denuncias de las víctimas y sus organizaciones (Abramovich, 2010).

Luego, durante las transiciones a la democracia en los ochenta y principios de los noventa, el Sistema amplió su margen de acción para acompañar los procesos dirigidos a la superación de los conflictos y de los regímenes dictatoriales. Para tal fin delineó los principios medulares de las transiciones políticas: los derechos a la justicia, a la verdad y a la reparación ante graves violaciones, masivas y sistemáticas, de derechos humanos. En este período también enfrentó el terrorismo de Estado del gobierno de Alberto Fujimori en el Perú y denunció las violaciones a los derechos humanos en el marco del conflicto armado colombiano además:

Fijó los límites de las leyes de amnistía. Sentó las bases para la protección estricta de la libertad de expresión y la prohibición de la censura previa. Invalidó los tribunales militares para juzgar civiles y casos de derechos humanos, limitando un espacio de acción de las fuerzas militares que eran todavía actores de veto en las transiciones y procuraban impunidad por los crímenes del pasado (Abramovich, 2010, p. 3).

Durante los procesos de transición a la democracia, buena parte de los Estados de la región latinoamericana, optaron por adoptar la fórmula del perdón y olvido. En este escenario se enfrentaron a los dilemas propios que se suscitan en torno a las exigencias de justicia frente a la impunidad y por otra parte la necesidad de adoptar mecanismos de flexibilización en materia penal para lograr la reconciliación (Orozco, 2002). Las organizaciones de víctimas y Organizaciones No Gubernamentales de derechos humanos cuestionaron los procesos de perdón y olvido porque consideraban que generaban impunidad frente a las graves violaciones de derechos humanos cometidos por los regímenes autocráticos (Miranda: 1999).

Fue así como las instancias de justicia internacionales y específicamente el Sistema Interamericano de Protección a los Derechos Humanos, fueron vistos por las víctimas y las ONG defensoras de derechos humanos, como un espacio importante para promover la superación de la impunidad y presionar a los Estados para adoptar medidas en favor de la verdad, la justicia y la reparación en los procesos de transición a la democracia.

En los tiempos actuales se configuran las transiciones democráticas, en las que existe una mejoría de los sistemas electorales, el respeto a la libertad de prensa y el abandono de la violencia política, sin embargo, este periodo coincide con deficiencias institucionales, como sistemas judiciales ineficientes o niveles significativos de desigualdad social y exclusión que amenazan la estabilidad institucional. Durante esta nueva etapa, el Sistema pretende incidir en la calidad de los procesos democráticos y en esa medida no solo se preocupa por la reparación de las víctimas. Esto explica por qué, en parte, temáticas como el funcionamiento de la administración de justicia, la preservación de la esfera pública en los sistemas democráticos desde la defensa y promoción de la libertad de expresión y la protección y defensa de la igualdad de grupos y colectivos, existe un interés relevante en el campo de acción estratégico del Sistema para fortalecer las condiciones institucionales internas en las que se desarrollen los procesos democráticos (Abramovich, 2010).

Esta breve caracterización permite evidenciar la transformación de la agenda estratégica del Sistema Interamericano que se desplaza de la protección de los principales derechos individuales en contextos de dictadura o conflicto armado en los que ocurrían violaciones sistemáticas a los DDHH, hacia la búsqueda de condiciones sociales y políticas para la consolidación de estos procesos democráticos, lo que podía concebirse como la lucha contra patrones estructurales de desigualdad social y 
fortalecimiento de los derechos de las minorías. El rol que ha desempeñado cada uno de los órganos del sistema, es decir la Comisión Interamericana de Derechos Humanos y la Corte Interamericana de Derechos Humanos así como sus funciones, que se encuentran plenamente diferenciadas para concurrir holísticamente al cumplimiento de los fines del mecanismo de protección, deben ser comprendidas en este contexto de cambio respecto de su intervención estratégica.

Por ejemplo, dentro de la competencia amplia que tiene la Comisión Interamericana, es decir la de promover la observancia y la defensa de los derechos humanos, se encuentran varias funciones que se relacionan con su protagonismo directo en el acceso a la justicia de los ciudadanos de los Estados de la OEA. Por ejemplo, a través de la interposición de demandas ante la Corte Interamericana, luego del trámite de las peticiones individuales, o el requerimiento a los Estados para que adopten medidas cautelares, así como la competencia para solicitarle a la Corte proferir medidas provisionales en determinados casos.

Sin embargo, otras funciones buscan fortalecer la incidencia del Sistema Interamericano más allá del ámbito jurídico o respecto de la realización al derecho a un recurso judicial efectivo de las personas, para posibilitar su intervención en escenarios, académicos, políticos y culturales, que ayuden a fortalecer los derechos humanos en los países de la región y los mandatos de la Convención Americana. De esta forma la Comisión a través de sus funciones de monitoreo, investigación y reflexión en estas temáticas, se convierte en un organismo muy importante en el proceso de globalización de los estándares en materia de derechos humanos. Es así como hoy en día en un significativo número de Estados se reconoce el valor de la jurisprudencia que emite, así como de los pronunciamientos que profiere; en efecto estos han tenido una relevancia creciente en la transformación de los sistemas judiciales de los países de la región, en la adopción de políticas públicas y en el accionar de la ciudadanía frente a los Estados para reivindicar sus derechos. Las diferentes experiencias en los países de la región, indican que el Sistema Interamericano ha tenido una incidencia muy importante en la orientación general de algunas políticas públicas, y en los procesos de formulación, implementación, evaluación y fiscalización de las mismas. De forma específica, la Comisión realiza recomendaciones tomando como base estándares jurídicos sobre políticas públicas en sus informes generales por países, donde analiza situaciones concretas de violaciones a los derechos humanos. De igual forma a través de sus informes temáticos, sobre materias de interés regional, o concernientes a varios estados, se fijan estándares y principios, al mismo tiempo que se relevan situaciones o problemas estructurales más allá de los casos individuales. El proceso de elaboración de los informes temáticos permite que la Comisión dialogue con actores sociales locales e internacionales relevantes, así como con los funcionarios de los Estados encargados de la puesta en marcha de las políticas (Abramovich, 2010).

Por otra parte, a través de la promoción de procesos de solución amistosa o negociaciones entre los peticionarios y los Estados, la Comisión Interamericana ha logrado que en muchos casos estos últimos se comprometan a implementar reformas institucionales o normativas, o a adoptar mecanismos de consulta con la ciudadanía para la definición de políticas públicas. Por ejemplo, a partir de estas interacciones se ha logrado la implementación de programas masivos de reparación de las víctimas de violaciones de derechos humanos o de comunidades afectadas por la violencia.

Específicamente, la Corte Interamericana de Derechos Humanos ha sido muy importante en la labor de fijar el alcance de las obligaciones estatales que emanan de la Convención Americana y, en esa medida, promover la globalización de los derechos humanos al interior de los países de la región, no solo a través de la función que desempeña como máximo juez en los casos contenciosos sino a través de la emisión de opiniones consultivas, en las que examina problemas concretos tales como la situación jurídica de los trabajadores migrantes, y los derechos humanos de niños y adolescentes. En estas opiniones consultivas en un significativo número de ocasiones la Corte ha hecho esfuerzos por fijar marcos jurídicos para el desarrollo de políticas (Abramovich, 2010) ${ }^{10}$.

10. “Así por ejemplo en la Opinión Consultiva 18 procura definir una serie de principios que deben orientar las políticas migratorias de los Estados, y en especial el reconocimiento de ciertos derechos sociales básicos a los inmigrantes en situación irregular. En la Opinión Consultiva 17 procura orientar las políticas dirigidas a la infancia imponiendo límites a las políticas criminales dirigidas a los niños" (Abramovich, 2010: 7). 
En ese sentido, los movimientos sociales que reivindican los derechos de las víctimas, han logrado fortalecer su acción política en escenarios locales a partir de la exigibilidad de derechos acudiendo, en buena medida, al reconocimiento de los estándares internacionales que promueven los derechos a la verdad, a la justicia y a la reparación integral. Así como en la responsabilidad de los Estados frente a la ocurrencia de hechos de violencia sistemática.

Para ilustrar este aspecto, hacemos un breve análisis de dos sentencias en las que se condena al Estado colombiano por violaciones a los Derechos Humanos y a partir de los cuales se adoptan una serie de parámetros sobre el derecho a la reparación integral.

\section{Reseña de sentencias del Sistema Interamericano sobre Colombia y su concepción de la reparación integral}

Antes de proceder al análisis de las sentencias respectivas, es importante hacer una brevísima caracterización del derecho a la reparación integral desde los desarrollos del derecho internacional, para comprender con mayores elementos la importancia del sentido y alcance de las medidas proferidas en dichos fallos y que han contribuido a fijar los estándares de protección de los derechos humanos de las víctimas en contextos de conflicto como ha ocurrido en Colombia.

El concepto y alcance del derecho a la reparación integral ha sufrido grandes transformaciones a lo largo del tiempo, gracias a la doctrina y a la jurisprudencia internacional, especialmente en cabeza de la Corte Interamericana de Derechos Humanos (C.I.D.H) en donde se ha entendido que este deber estatal es uno de los principios fundamentales en materia de la promoción y prevención de violaciones a los derechos humanos.

Si se toma lo dicho en el principio 33 de los Principios de Joinet, denominado "Derechos y deberes nacidos de la obligación de reparar" se encuentra ya un concepto de reparación exigible para todos los Estados: "Toda violación de los derechos humanos hace nacer un derecho a la reparación en favor de la víctima, de sus parientes o compañeros que implica, por parte del Estado, el deber de reparar y la facultad de dirigirse contra el autor".
De la lectura anterior se colige que surge la obligación de los Estados a reparar a partir de la ocurrencia de una violación a los derechos humanos, sin embargo, recientemente esa obligación se concibe de forma más amplia teniendo en cuenta que esta mira incluso hacia la erradicación de las condiciones que propiciaron las violaciones a los derechos humanos, tal y cómo se ha establecido, por ejemplo, en las sentencias que se analizarán en la última parte de este texto.

Así las cosas se dice que el derecho a la reparación no tiene únicamente una dimensión resarcitoria respecto de quienes fueron víctimas de violaciones a sus derechos, sino que tiene a su vez una dimensión política que propende por la asunción del Estado de un rol positivo e interventor que tenga como finalidad la transformación de las estructuras sociales que fueron la causa de las violaciones a los derechos humanos, estas medidas están encaminadas a la democratización del Estado y de la sociedad, sobre todo en contextos de conflicto armado.

Por las finalidades de este artículo, no es posible desarrollar con mayor profundidad esta idea, por lo que a continuación se efectúa una breve caracterización esquemática sobre lo que se ha considerado como los elementos principales del derecho a la reparación integral, al menos en su dimensión individual:

(1) Restitución: La cual debe estar orientada a devolver a la víctima a la situación anterior a la violación de las normas internacionales de derechos humanos o del Derecho internacional humanitario (DIH), comprende el restablecimiento de la libertad, los derechos, la situación social, la vida familiar y la ciudadanía de la víctima; el retorno a su lugar de residencia, la reintegración en su empleo y la devolución de sus propiedades, entre otras medidas.

(2) Indemnización: Entendida como la compensación monetaria de todo perjuicio evaluable económicamente que fuera consecuencia de una violación de las normas internacionales de derechos humanos o del Derecho internacional humanitario, tales como el daño físico o mental, la pérdida de oportunidades, los daños materiales y la pérdida de ingresos, entre otros.

(3) Rehabilitación: debería incluir la atención médica y psicológica, así como servicios jurídicos y sociales. 
(4) Satisfacción y garantías de no repetición: Deberían incluir, cuando fuere necesario, el cumplimiento de algunas de las medidas atendiendo a las circunstancias especiales de cada caso, incluye medidas como la cesación de violaciones continuadas; verificación de lo sucedido, difusión pública y completa de la verdad, la búsqueda de los cadáveres de las personas desaparecidas, una declaración oficial que restablezca la dignidad, honra y buen nombre de las víctimas; aceptación de responsabilidades; la adopción de sanciones judiciales o administrativas a los responsables; conmemoraciones y homenajes a las víctimas; entre otras.

En este mismo sentido el denominado estatuto de Roma, en su artículo 75, se refiere al derecho de las víctimas en el marco de las investigaciones y juicios que se adelanten por la comisión de delitos de competencia de la Corte Penal Internacional. Para la Corte penal este derecho se compone de medidas de restitución, indemnización y rehabilitación que serán definidas por el Tribunal en cada caso en concreto.

Luego de esta breve caracterización se procede a efectuar el análisis de las sentencias paradigmáticas escogidas.

2.1 Caso de la Masacre de pueblo Bello, sentencia de 31 de enero de 2006

Entre el 13 y 14 de enero de 1990, un grupo de aproximadamente 60 hombres fuertemente armados, pertenecientes a una organización paramilitar creada por Fidel Antonio Castaño Gil denominada "Los Tangueros", por la relación de éstos con su finca "Las Tangas", salieron de la finca "Santa Mónica" de su propiedad, ubicada en el municipio de Valencia, Departamento de Córdoba. Su propósito era realizar un ataque en el corregimiento de Pueblo Bello, para secuestrar a un grupo de individuos presuntamente colaboradores de la guerrilla con base en una lista de la que eran portadores. Los criminales dispusieron la entrada de cuatro camiones de paramilitares con prendas de uso privativo de las fuerzas militares y algunos vestidos de civil para que ingresaran al pueblo para efectuar asesinatos selectivos en contra de la población civil, sindicada de ser perteneciente o auxiliadora de la guerrilla. Fueron torturadas y masacradas 37 personas, quedando tan solo 5 sobrevivientes, en la zona existían varios retenes de las fuerzas militares que controlaban la salida y entrada de vehículos.
La Corte estableció que el Estado luego de haber sido el causante de la creación y del posterior fortalecimiento de los grupos paramilitares, no tomó los correctivos necesarios ni adecuados ni suficientes para combatirlos y de esta forma contribuir a su obligación internacional de respetar los derechos establecidos en la convención Americana. De esta forma, si bien el Estado al momento de los hechos, mantenía una política que establecía que el paramilitarismo era un delito susceptible de ser sancionado conforme a los procedimientos internos, no tomó las medidas necesarias para hacer real y efectiva esta prescripción.

Esta postura se conceptualiza a través de la teoría denominada del "riesgo excepcional", bajo la cual se obliga a los Estados a hacer cesar las violaciones y los daños ocasionados a sus ciudadanos con ocasión de situaciones que fueron causadas por las acciones $\mathrm{y} / \mathrm{u}$ omisiones del mismo Estado.

Respecto de este caso, la Corte Interamericana estableció que dentro de las partes lesionadas debería incluirse tanto a las víctimas como a sus familiares, por las violaciones a sus derechos a la vida e integridad personal, las garantías judiciales y a la protección judicial. Respecto de los perjuicios materiales causados, la Corte estableció que no contaba con los medios probatorios adecuados para determinar el monto del daño cierto, sin embargo, tuvo en cuenta que las victimas en general tuvieron que afrontar una situación de desplazamiento forzado que les hacía muy gravosa su situación y que les impedía aportar al proceso ante la Corte los comprobantes correspondientes. Por esta razón, acudiendo a criterios de equidad, decidió indemnizar a las victimas teniendo en cuenta la proyección de sus ingresos y su expectativa de vida. Respecto de los perjuicios inmateriales, la Corte decidió exonerar de la carga de la prueba a los demandantes, para sostener que estos se presumen, en efecto, sostuvo que el hecho de la muerte desaparición de estas personas implicaba un sentimiento de dolor tan evidente que resultaba inocuo e innecesario probar; por esta razón ordenó sendas indemnizaciones a las victimas acogiendo varios criterios de equidad.

En cuanto a las medidas de satisfacción y de garantías de no repetición, la Corte ordenó al Estado prestar a las victimas asistencia 
médica y psicológica para mitigar los perjuicios ocasionados con la masacre, así mismo lo conminó a adelantar programas de restitución de vivienda para los pobladores de Pueblo Bello, que perdieron su lugar de residencia por los efectos del conflicto armado. Finalmente ordenó el empleo de todos los medios necesarios para erradicar la impunidad y en un tiempo razonable identificar, juzgar y sancionar a los responsables de la masacre, en este apartado también se ordenó la plena identificación de los cadáveres, la publicación de la sentencia en un medio de amplia difusión nacional y la realización de un acto público por parte del Estado en donde reconociera su responsabilidad en la masacre y se comprometiera a prestar la debida seguridad al municipio de Pueblo Bello, garantizando, además, la no repetición de dichos acontecimientos.

2.2 Sentencia del caso de la masacre de la Rochela contra Colombia 11 de mayo de 2007

Los hechos del caso ocurrieron en el municipio de la Rochela en el departamento de Santander el 18 de enero de 1989, lugar al cual se desplazó una Comisión judicial integrada por 15 miembros pertenecientes a la rama judicial, al cuerpo técnico de investigación y la Fiscalía general de la Nación, quienes estaban investigando hechos relacionados con graves violaciones a los derechos humanos, entre los que figuraba la muy conocida masacre de los 19 comerciantes ocurrida en octubre de 1987 la cual fu efectuada por el grupo Paramilitar "Los masetos", caso que fue resuelto en contra del Estado Colombiano por parte de la Corte Interamericana.

Esta comisión judicial, fue interceptada por un grupo de hombres fuertemente armados pertenecientes al grupo paramilitar, quienes se identificaron como miembros de la guerrilla de las FARC, estos hombres procedieron a retener a los miembros de la comisión por algunas horas en un sitio desconocido, mientras les hacían preguntas respecto de los expedientes judiciales que portaban, luego los condujeron en un vehículo particular a un sitio denominado "La laguna", municipio custodiado por dos guarniciones militares, allí fueron masacrados y previamente despojados de varios de los expedientes que portaban, tan solo tres de las 15 personas sobrevivieron.

Ante la Corte resulto evidente que el Estado estableció un marco legal a través del cual se propició “la creación de grupos de autodefensa, que contaban con el apoyo de las autoridades estatales y que derivaron en paramilitares. El Estado les otorgaba permisos para el porte y tenencia de armas de uso privativo de las Fuerzas Armadas"11, que "Las violaciones ocurrieron en una época en que ese marco legal se encontraba vigente, a pesar de que ya habían transcurrido varios años desde que se hizo notoria la transformación de grupos de autodefensa en paramilitares", que "Miembros del Ejército promovieron la formación del grupo paramilitar "Los Masetos", que perpetró la masacre de La Rochela, y le brindaban apoyo". Además determinó que "el Ejército utilizaba a miembros del grupo paramilitar "Los Masetos" como guías, incluso realizando acciones de patrullaje de manera conjunta y dotándolos de armamento militar" y, finalmente, que "el Estado reconoce que los miembros del grupo paramilitar "Los Masetos" contaron con la cooperación y aquiescencia de agentes estatales para ejecutar la Masacre de La Rochela"12. Conforme a lo anterior, la Corte estableció que la masacre de la Rochela no se produjo como un hecho aislado en el contexto de violencia que afronta Colombia desde hace varios años, por el contrario, ese contexto era determinante en la atribución de responsabilidad por los hechos ocurridos el 18 de enero de 1989 en el departamento de Santander, que evidenciaron una práctica sistemática de violación de derechos humanos encaminada a amedrentar a los funcionarios judiciales, con el fin de que tuvieran temor al momento de realizar investigaciones de graves violaciones de derechos humanos y de esta forma obstruirlas.

Frente a las obligaciones de reparación en cabeza del Estado, en esta sentencia se reitera la concepción que al respecto ha defendido en su jurisprudencia, donde se plantea que esta debe ser integral y adecuada, en el marco de la Convención, exigiendo que esta contemple medidas de rehabilitación, satisfacción, y garantías de no repetición.

La Corte observa que las decisiones adoptadas por los tribunales internos, específicamente de la jurisdicción de lo contencioso administrativo, no contienen

11. Corte IDH. Caso La Rochela Vs Colombia. Sentencia de 11 de mayo de 2007. Párrafo 101.

12. Ibíd. Corte IDH. Párrafo 101. 
una manifestación de responsabilidad estatal por la violación de derechos como la vida y la integridad personal, entre otros derechos consagrados en la Convención. De igual manera, no contiene aspectos relativos a la rehabilitación, la verdad, la justicia y el rescate de la memoria histórica, así como tampoco medidas de garantía de no repetición. La Corte estimó que la reparación integral de una violación a un derecho protegido por la Convención no puede ser reducida al pago de compensación a los familiares de la víctima ${ }^{13}$.

De igual manera la Corte Interamericana, sostuvo que si bien las víctimas o sus familiares deben tener amplias oportunidades también en la búsqueda de una justa compensación en el derecho interno, este deber no puede descansar exclusivamente en su iniciativa procesal o en la aportación privada de elementos probatorios. De tal manera, en los términos de la obligación de reparación integral que surge como consecuencia de una violación de la Convención ${ }^{14}$, el proceso contencioso administrativo no constituye per se un recurso efectivo y adecuado para reparar en forma integral esa violación ${ }^{15}$.

La Corte ha indicado que recursos como la acción de reparación directa o la acción de nulidad y restablecimiento del derecho, mecanismos internos para establecer la responsabilidad del Estado, tienen unos alcances mínimos y unas condiciones de acceso no apropiadas para los fines de reparación que la Convención Americana establece, criterio que es retomado en este caso para sostener que es la producción de un daño antijurídico y no la responsabilidad del Estado ante el incumplimiento de estándares y obligaciones en materia de derechos humanos lo que decreta en su jurisdicción interna, una atribución de responsabilidad en el ámbito interno. Criterios disímiles que no dan cuenta de las diferencias existentes entre los fundamentos de la responsabilidad del Estado en su sistema judicial y la responsabilidad del Estado ante el sistema interamericano.

13. Ibid. CIDH. Párrafo 206.

14. Ibid. CDIDH. Párrafo 226.

15. Ibid. CIDH. Párrafo 209, en las citas de la Corte se reiteran varias sentencia: Caso de las Masacres de Ituango, Párr. 340; y Caso de la Masacre de Pueblo Bello, Párr. 209.
Finalmente, la Corte ordenó reparar a todas las víctimas, tanto las que fallecieron como a los familiares de estas y a los sobrevivientes, estableciendo indemnizaciones pecuniarias a cada uno de estos por perjuicios tanto materiales como inmateriales. Por otra parte como medidas de satisfacción y de no repetición, se destacan las de ordenar al Estado la investigación, identificación y sanción de los responsables de la masacre; la de exigir al Estado medidas concretas para la protección a los operadores judiciales que les permita realizar sin ningún obstáculo su labor; la de asistir médica y psicológicamente a los familiares de las víctimas que perecieron y a las víctimas sobrevivientes; y la de establecer medidas educativas mediante el establecimiento de becas en derechos humanos para que la comunidad en general recuerde lo sucedido y se promuevan los derechos humanos en el país.

\section{CONCLUSIONES}

Los Derechos Humanos cuentan hoy en día con un amplio y difundido reconocimiento internacional, en buena medida los órganos creados para su defensa y protección que surgen desde mediados del siglo XX han tenido un papel muy importante en su desarrollo. En América Latina, el Sistema Interamericano de Protección a los Derechos Humanos de la OEA ha sido fundamental en el fortalecimiento del acceso a la justicia de los ciudadanos, frente a situaciones que han afectado de forma grave los derechos humanos desde la década de los setenta, cuando prevalecían gobiernos autoritarios y dictaduras.

Debido al protagonismo del Sistema Interamericano y a su importancia en la promoción de la democracia y la exigibilidad de derechos, en el presente artículo se analizó su potencialidad para promover el fortalecimiento del acceso a la justicia en la región, contextualizando su análisis en la variación de su orientación estratégica en las últimas tres décadas, que puede resumirse en la búsqueda inicial por denunciar y documentar la vulneración sistemática de derechos humanos durante regímenes autoritarios en los ochenta; el acompañamiento de las transiciones políticas hasta mediados de los noventa y por último, la búsqueda de la consolidación de las democracias, especialmente a partir de la protección a las minorías y la lucha contra factores de desigualdad social, en las dos últimas décadas. 
Específicamente la jurisprudencia del Sistema Interamericano ha logrado incidir de manera significativa en la normatividad interna, dando lugar a una serie de interacciones que denotan un grado significativo de incorporación de los estándares internacionales en los países de la región. Fenómeno que también no ha estado excepto de resistencias y tensiones. Sin embargo, la Corte Interamericana de Derechos Humanos ha logrado fijar el alcance de las obligaciones estatales que emanan de la Convención Americana $y$, en esa medida, promover la globalización de los derechos humanos, no solo a través de la función que desempeña como máximo juez en los casos contenciosos sino a través de la emisión de opiniones consultivas, en las que examina problemas concretos con relevancia en los derechos humanos.
Sin lugar a dudas el Sistema Interamericano continúa siendo un espacio importante para promover la lucha por los derechos humanos y robustecer los objetivos más amplios de democratización, desde abajo, que promueven los movimientos sociales y que van más allá de la sanción a los responsables de crímenes de lesa humanidad. Un ejemplo de lo anterior lo podemos encontrar en las sentencias analizadas, ya que a partir de los estándares fijados por la Corte, se configuran una serie de prescripciones normativas que dinamizan el debate interno sobre el concepto de reparaciones y que sirven a la sociedad civil y a la administración de justicia para fundamentar sus reclamos de exigibilidad frente a violaciones a los derechos humanos y promover valores democráticos.

\section{BIBLIOGRAFÍA}

- ABRAMOVICH, Victor \& COURTIS Christian, Los derechos sociales como derechos exigibles, Editorial Trotta, Madrid, 2004.

- ABRAMOVICH, Victor, De las violaciones masivas a los patrones estructurales. Nuevos enfoques y clásicas tensiones en el sistema interamericano de derechos humanos. 2010.

- AGUILAR-Aranguren, Asdrúbal, Apuntes sobre medidas cautelares en la Convención Americana sobre Derechos Humanos, en la Corte y el Sistema Interamericano de Derechos Humanos, Rafael Nieto Navia (Editor) Corte Interamericana de Derechos Humanos, 1994.

- ALEXY, Robert. Sistema jurídico, principios jurídicos y razón práctica, en: Derecho y razón práctica. Distribuciones Fontanarama. Primera edición. Méjico. 1993.

- ANTEQUERA, José Darío, La memoria histórica como relato emblemático, Alcaldía Mayor de Bogotá, 2011.

- AYALA Carlos, "La independencia de la justicia y los procesos constituyentes en la región Andina", en Revista de estudios constitucionales, año 6, № 1, 2008, pp. 345358 , Centro de estudios constitucionales de
Chile, Universidad de Talca, 2008.

- CARVAJAL, Jorge, La Seguridad en el Estado de garantías", Instituto Latinoamericano de Servicios Legales Alternativos ILSA, Bogotá, Colombia, 2009.

- BARBOSA, Francisco, Litigio Interamericano, Universidad de Bogotá Jorge Tadeo Lozano, Bogotá, Colombia, 2002.

- BOTERO, Catalina y RESTREPO, Esteban. "Estándares internacionales y proceso de transición en Colombia". ¿Justicia transicional sin transición? Verdad, justicia y reparación para Colombia. Centro de Derecho, Justicia y Sociedad, dejusticia. Bogotá: Ediciones Antropos, 2006.

- CANÇAO-TINDADE, Antonio y AYALA, Carlos, Eficacia jurídica de las resoluciones de la comisión y corte interamericana de derechos humanos y su comparación con otros sistemas, Corte Interamericana de Derechos Humanos, 1999.

- FAUNDEZ, Héctor, El Sistema Interamericano de Protección de Derechos Humanos. Aspectos Institucionales y procesales. Tercera edición, Instituto Interamericano de Derechos Humanos, 2004.

- GARCÍA, Álvaro, "Los derechos humanos 
en el derecho internacional", en Derechos Humanos en Colombia 25 años Itinerario de una Historia - comité Permanente por la Defensa de los Derechos Humanos - Bogotá, Colombia, 2004.

- GARCÍA, Sergio, "El futuro del sistema interamericano de protección de los derechos humanos", en boletín Mexicano de derecho comparado, mayo- agosto, año/ vol, número 101, Universidad Autónoma de México, Pp, 653-683, 2001.

- GARCÍA, Sergio, "El acceso de la víctima a la jurisdicción internacional sobre derechos humanos", Instituto Interamericano de Derechos Humanos, 2009.

- GUZMÁN Rincón Andrés Mauricio, "Políticas públicas y derechos humanos: puntos de convergencia en contextos democráticos". En: Criterio Jurídico Garantista ISSN: 2145-3381 ed: Universidad Autónoma de Colombia, v.9 fasc. N/A p.120 - 137, 2013.

- KELSEN Hans. Teoría general del Estado. Editorial Nacional. Buenos Aires. 1979.

- MIRANDA, Javier, "Enfoques de Naciones Unidas sobre impunidad y reparación", en Verdad y Justicia, procesos de paz y transición a la democracia, Bogotá, Colombia, 2009.

- OROZCO, Iván, "Posguerra en Colombia: Divagaciones sobre la venganza, la justicia y la reconciliación" en Revista Análisis Político, No 46, Universidad Nacional de Colombia, Bogotá, 2002.

- RODRÍGUEZ Garavito, César, “Globalización, reforma judicial y Estado de derecho en Colombia y América Latina: el regreso de los programas de derecho y desarrollo", en ¿Justicia para todos? Sistema judicial, derechos sociales y democracia en Colombia, Norma, Bogotá, 2005.

- SIEDER, Rachel (Ed), La judicialización de la política en América latina, Universidad Externado de Colombia, Bogotá, 2007.

- PNUD, "Manual de políticas públicas para el acceso a la Justicia. América latina y el Caribe", serie documentos de trabajo, Buenos Aires Argentina.

- VENTURA, Manuel, "La Corte Interamericana de Derechos Humanos Camino hacia un Tribunal permanente", Rio de Janeiro, 2001.

- VINYES, Ricard. "La memoria como política pública". En: Guixé, Jordi e Iniesta, Montserrat (eds.) "Políticas públicas de la memoria". I Coloquio Internacional Memorial Democratic. Barcelona: Editorial Milenio, 2009.

\section{Jurisprudencia y normatividad}

- Comité CEDAW, Recomendación General No. 19, La Violencia contra la mujer, $11^{\circ}$ periodo de sesiones, 1992, Doc. HRI/ GEN/1/Rev.1 at 84, 1994.

- Comité CEDAW, Recomendación General No. 12, La violencia contra la mujer, Octavo periodo de sesiones, 1989, Doc. HRI/ GEN/1/Rev.1 at 78, 1994.

- Convención americana sobre derechos humanos suscrita en la conferencia especializada interamericana sobre derechos humanos. San José, Costa Rica 7 al 22 de noviembre de 1969.

- Corte Constitucional Colombiana Sentencia C 370 de 2006.

- Corte Interamericana de Derechos Humanos, Sentencia del Caso de la masacre de la Rochela vs. Colombia, 11 de mayo de 2007.

- Corte Interamericana de Derechos Humanos, Asunto del Internado Judicial Capital El Rodeo I y El Rodeo II. Medidas Provisionales respecto de Venezuela. Resolución de la Corte Interamericana de Derechos Humanos de 8 de febrero de 2008.

- Corte Interamericana de Derechos Humanos, Caso James y otros. Medidas Provisionales. Resolución de la Corte Interamericana de Derechos Humanos de 26 de noviembre de 2001.

- Corte IDH. Caso de las Masacres de Ituango Vs. Colombia. Sentencia de 1 de julio de 2006. 